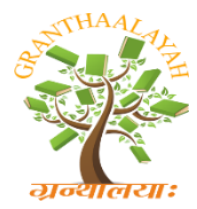

Social

\section{INTERNATIONAL JOURNAL OF RESEARCH GRANTHAALAYAH A knowledge Repository}

\title{
IMPACT OF PREJUDICE ON SOCIAL BEHAVIOR
}

\author{
Dr. Paras Jain ${ }^{\mathbf{1}}$, Roshni Billaiya ${ }^{2}$, Shivangi Jain ${ }^{3}$ \\ ${ }^{1}$ Director, Silicobyte Katni Degree College, Dikshabhumi Campus, Adharkap, Katni, M.P, India \\ ${ }^{2}$ Registrar, Silicobyte Katni Degree College, Dikshabhumi Campus, Adharkap, Katni, M.P, India \\ ${ }^{3}$ OSD, Silicobyte Katni Degree College, Dikshabhumi Campus, Adharkap, Katni, M.P, India
}

\begin{abstract}
Everyone whether it is human or animal influence by prejudice nature and behave socially according to prejudiced thinking. It influences negatively preventing to handle situations, persons with new perspective. It acts as barrier for nurturing new ideas and thinking development. It affects decision making power of a person. Present study is targeted to measure prejudice nature and finding its impact on social behavior.
\end{abstract}

Keywords: Prejudice; Social Behaviour.

Cite This Article: Dr. Paras Jain, Roshni Billaiya, and Shivangi Jain. (2018). "IMPACT OF PREJUDICE ON SOCIAL BEHAVIOR." International Journal of Research Granthaalayah, 6(6), 518-521. https://doi.org/10.29121/granthaalayah.v6.i6.2018.1397.

\section{Introduction}

Prejudice is the act of making general assumptions of a person or a community based on limited understanding. This action creates ignorance about a person, community and a generalization of a larger demographic. Prejudiced people rely on stereotypes to inform themselves about what they think they need to know about a person. Prejudice is the gateway to hurtful and intentional racism, homophobia and inferiority and superiority complex. Prejudice can have a range of influences and it is impossible to predict the impact on each individual.

Prejudiced persons exclude themselves from opportunities to learn and grow which is harmful for development of own, society and culture. Prejudice also prevents that person from a chance to learn about a community from that community's perspective. People are prejudice because of rumors, bad experiences, needs to process lots of information and to make quick assessments, especially in unfamiliar situations.

Prejudiced persons are unable to take right decision, it greatly influences what people expect from the future and how they feel about their chances for self-improvement, referred to as their life chances. Prejudice can impose very dramatic barriers or invisible barriers on individuals. 


\section{Objective}

- Finding of prejudice nature among male and its impacts on Social Behavior

- Finding of prejudice nature among female and its impacts on Social Behavior

\section{Hypothesis}

1) There is no significant prejudice nature among male and no significant impact on social behavior.

2) There is no significant prejudice nature among female and no significant impact on social behavior.

\section{Methodology}

Descriptive survey method was applied for this study. 150 male and 150 female persons of age 3150 years were randomly selected as sample. 50\% rural and 50\% urban were accompanied in sample. They were tested for finding of value of prejudice nature and its impact on social behavior. Sample was classified according to gender and age group wise. Collected data was tabulated and comparatively analyzed using percentile as statistical tool.

\section{Finding and Analysis}

Table 1: Status of Prejudice Nature among Male and Female

\begin{tabular}{|l|l|l|l|l|l|}
\hline Gender & Age Group & \multicolumn{4}{|c|}{ No. of Persons \% } \\
\cline { 3 - 6 } & & \multicolumn{4}{|c|}{ Value of Prejudice } \\
& & $\mathbf{0 - 1 0}$ & $\mathbf{1 1 - 2 0}$ & $\mathbf{2 1 - 3 0}$ & $\mathbf{3 1 - 4 0}$ \\
\hline \multirow{4}{*}{ Male } & 21-30 Year & 38 & 35 & 19 & 8 \\
\cline { 2 - 6 } & 31-40 Year & 22 & 38 & 27 & 13 \\
\cline { 2 - 6 } & 41-50 Year & 12 & 36 & 33 & 19 \\
\hline \multirow{4}{*}{ Female } & 21-30 Year & 31 & 37 & 21 & 11 \\
\cline { 2 - 6 } & 31-40 Year & 11 & 41 & 32 & 16 \\
\cline { 2 - 6 } & 41-50 Year & 8 & 37 & 36 & 19 \\
\hline
\end{tabular}

Data table shows that among male of age $21-30$ years, $38 \%$ have $0-10,35 \%$ have $11-20,19 \%$ have 21-30 and 8\% have 31-40 prejudice value. Data value reached 12\%, 36\%, 33\% and 19\% for age group 41-50 year male persons. Impact of prejudice on social behavior of male related data indicates that among age group 21-30 years, 37\% are highly, $41 \%$ average and $23 \%$ low influenced. It varies to $42 \%$ high, $37 \%$ average and $21 \%$ low for age group $31-40$ years. $47 \%$ high, $35 \%$ average and 18\% are low influenced for age group 41-50 year male. Hence hypothesis 1, there is no significant prejudice nature among male and no significant impact on social behavior is rejected. 
Table 2: Status of Impact of Prejudice on Social Behavior

\begin{tabular}{|l|l|l|l|l|}
\hline \multirow{2}{*}{ Gender } & \multirow{2}{*}{ Age Group } & \multicolumn{3}{|c|}{ Impact on Social Behavior } \\
\cline { 3 - 5 } & & \multicolumn{3}{|c|}{ Value of Impact } \\
& & High & Average & Low \\
\hline \multirow{4}{*}{ Male } & $21-30$ Year & 37 & 41 & 23 \\
\cline { 2 - 5 } & $31-40$ Year & 42 & 37 & 21 \\
\cline { 2 - 5 } & $41-50$ Year & 47 & 35 & 18 \\
\hline \multirow{5}{*}{ Female } & $21-30$ Year & 42 & 32 & 26 \\
\cline { 2 - 5 } & $31-40$ Year & 46 & 28 & 26 \\
\cline { 2 - 5 } & $41-50$ Year & 48 & 33 & 19 \\
\hline
\end{tabular}

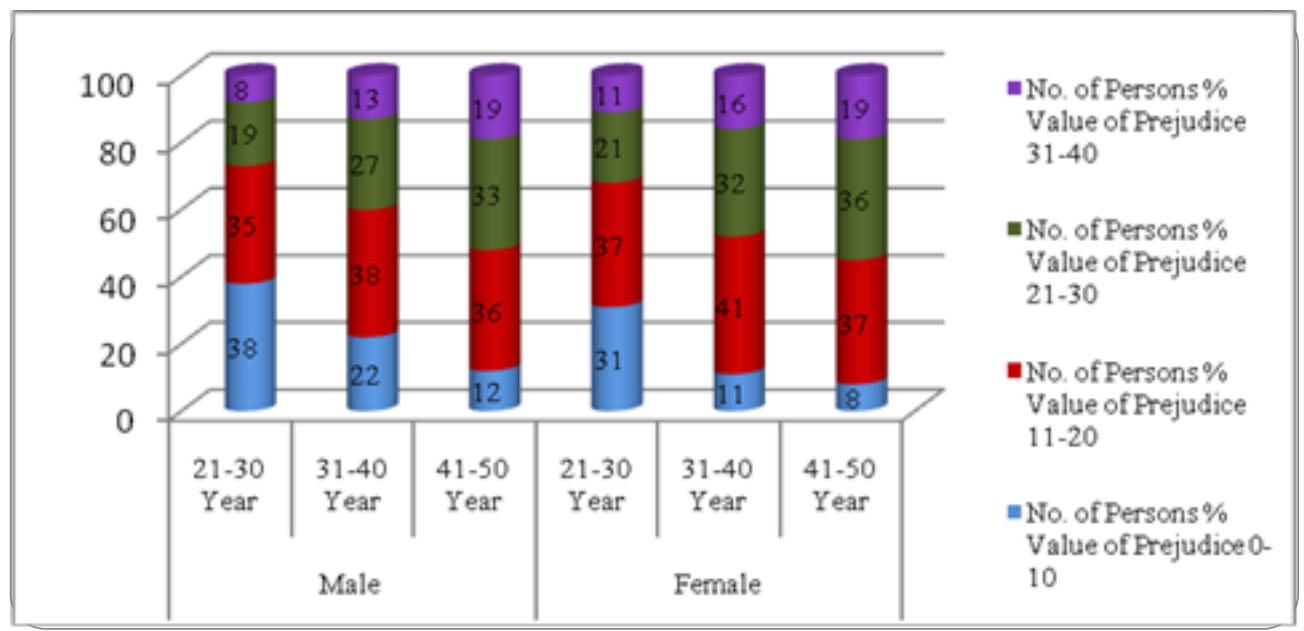

Chart 1: Status of Prejudice Nature among Male and Female

Among females, for age group 21-30 years, 31\% show 0-10, 37\% show 11-20, 21\% show 21-30 and $11 \%$ show $31-40$ prejudice nature. For age group $41-50$ years, data observed as $8 \%, 37 \%, 36 \%$ and $19 \%$ respectively. For $21-30$ year female, $42 \%$ high, $32 \%$ average and $26 \%$ low influence observed. Among 31-40 year females, 46\%, 28\% and 26\% are high, average and low affected. For 41-50 year old female, $48 \%, 33 \%$ and $19 \%$ are impacted respectively. Thus hypothesis 2 , there is no significant prejudice nature among female and no significant impact on social behavior is rejected.

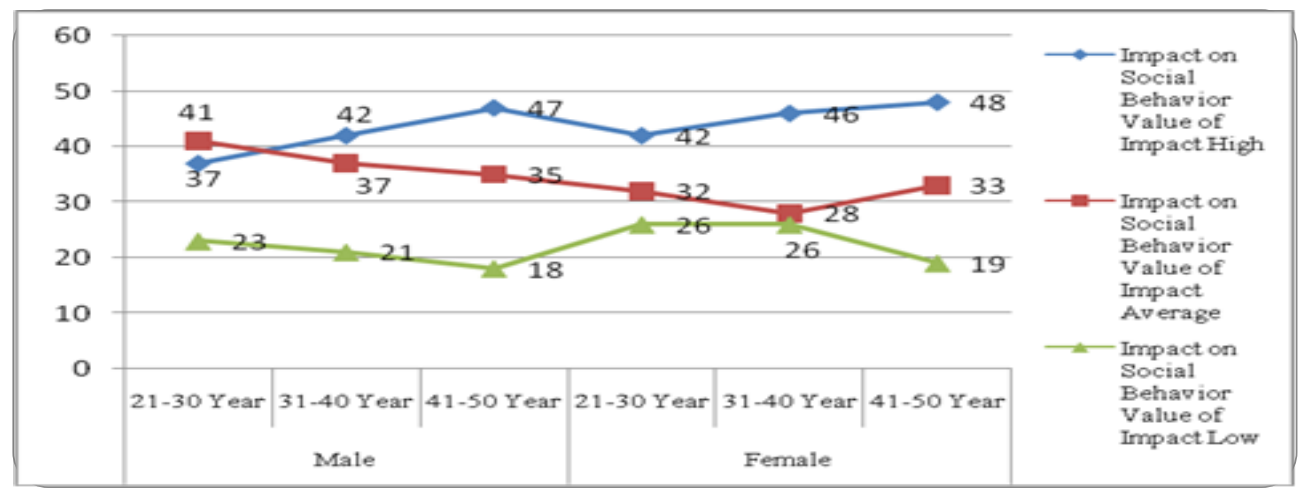

Chart 2: Status of Impact of Prejudice on Social Behavior 


\section{Conclusion}

Everyone has prejudice nature in different extent. This nature increases with age because people start to think on the basis of experience and it turns into prejudiced nature. No. of female having prejudice nature is greater than male. It creates a boundary for thinking level and prevents to think beyond boundary. Such people see others through spec of prejudice nature which nurtures hurdles to develop social behavior.

\section{References}

[1] Cherry, F., The nature of The Nature of Prejudice, Journal of History of Behavoral Science, 2000 Autumn;36(4).

[2] Plous, S., The Psychology of Prejudice: An Overview, Social Psychology Network, 2002.

[3] Katz, I., The Nature of Prejudice, Political Psychology, Vol. 12, No. 1, Mar., 1991

\footnotetext{
*Corresponding author.

E-mail address: parasjainkatni@gmail.com
} 